\title{
Assessment of factors associated with poor glycemic control among patients with Type II Diabetes mellitus
}

\author{
Ashutosh A Kakade ${ }^{1}$, Ipseeta R Mohanty ${ }^{1 *}$ and Sandeep Rai ${ }^{2}$ \\ ${ }^{1}$ Department of Pharmacology, MGM Medical College, India \\ ${ }^{2}$ Department of Medicine, MGM Medical College, India
}

\begin{abstract}
Background: Glycemic control remains the major therapeutic objective for prevention of target organ damage and other complications arising from diabetes. In addition, elucidation of various determinants of poor glycemic control may contribute to a clearer understanding of modifiable antecedents of diabetes-related complications and help to achieve improved diabetic control and patient outcomes.

Method: Two hundred twenty patients of Type II diabetes mellitus were taken after Informed consent. Patients who fulfill Inclusion and Exclusion Criteria were participated for the study. A Case record form was administered to these patients, which included details regarding the socio-demographic, anthropometric, metabolic, disease profile and diabetes self-care practices of the Type II diabetic patients.

Result: Based on HbA1c values, majority of diabetic patients had poor glycemic control (91.8\%) while only 8.2\% Type II diabetic patients had good (ideal) glycemic control. Statistically significant difference $(\mathrm{P}=0.044)$ was found between patients with good and poor glycemic control in relation with $\mathrm{BMI}(\mathrm{P}=0.044)$, central obesity $(P<0.001)$, dyslipidemia $(P<0.001)$ and diabetes self-care practices \{glucose management $(P=0.003)$, dietary control $(P=0.006)$, sum scale $(P=0.028)$ \}.
\end{abstract}

Conclusion: Majority of Type II diabetic patients had poor glycemic control. Factors affecting glycemic control included BMI, central obesity, dyslipidemia and diabetes self-care practices (glucose management and dietary control).

\section{Introduction}

There is a rising trend in the prevalence of diabetes in India over recent years, and the number of people living with diabetes in India is expected to increase from 32.7 million in the year 2000 to almost 60 million by 2025 [1]. In India, only a few nationwide studies have been conducted on the prevalence of diabetes and its complications. Moreover, while the urban population has easier access to diabetes screening as well as health care facilities for its management, the rural areas have poor diabetes screening services, preventive and counselling facilities, and there is non-adherence to diabetic management guidelines, complicated by long distance travel to health services among several other problems [2].

The primary goal in the management of diabetes mellitus is to attend near-normal glycaemia. Glycosylated hemoglobin (HbAlc) is the primary target of glycemic control. HbAlc is formed by nonenzymatic covalent addition of glucose moieties to hemoglobin in red cells. Unlike blood glucose levels, HbAlc is the index that indicates the average blood glucose during the past 3 months and is little affected by day-to-day variations [3]. Glycemic control is always the major therapeutic objective for prevention of target organ damage and other complications arising from diabetes. Despite the evidence from large randomized controlled trials establishing the benefit of improved glycemic control in reducing microvascular and macrovascular complications, high proportion of diabetic patients remain poorly controlled [4]. Therefore, recognizing the determinants of poor glycemic control will contribute to a clearer understanding of modifiable antecedents of diabetes-related complications and help to achieve improved diabetic control.
In clinical practice, optimal glycemic control is difficult to obtain on a long-term basis because the reasons for poor glycemic control in Type II diabetes are complex. Both patient and health care provider related factors may contribute to poor glycemic control. A variety of factors are identified in influencing glycemic control including age, sex, education, marital status, BMI, smoking, diabetes duration, and type of medications [5]. However, the results are not consistent and, in most instances, more than half of the variance in HbAlc levels is not explained [6]. Therefore studies focused on determining the factors predominantly associated with poor glycemic control among Type 2 diabetics attending any particular hospital set up, are warranted so that appropriate interventions can be planned at the level of the patient, physician and Institute.

This kind of research into diabetes mellitus will provide useful insights into the current glycemic control of diabetic patients in our set up. Type II diabetic patients were classified as having good and poor glycemic control. Data on glycemic control pattern was linked to various measures of treatment modality (Oral Hypoglycemic agents, Insulin, OHA + Insulin), risk factors (Hypertension, Dyslipidemia,), socio-demographic (Age, Gender, Socio-economic status), metabolic (Lipid Profile), anthropometric (BMI, Waist Circumference), disease

*Correspondence to: Ipseeta R Mohanty, Department of Pharmacology, MGM Medical College, Navi Mumbai 410209, India, E-mail: ipseetamohanty@yahoo.co.in

Key words: glycemic control, type ii diabetes mellitus, self-care practices, glycosylated hemoglobin

Received: June 10, 2018; Accepted: June 26, 2018; Published: June 29, 2018 
profile (complications of diabetes, duration of diabetes) as well as the diabetes self-care (Glucose Management, Dietary Control, Physical Activity and Health-Care Use) practices of type II diabetes patients.

\section{Materials and methods}

Approval from the Institutional Ethics Committee was obtained before initiating the study.: Approval No: 2015/SC/48

\section{Study design}

The study duration was one and half years. The study was an Observational, Cross-sectional, Descriptive type of study carried out in the department Medicine, MGM Medical College, Kamothe, Navi Mumbai.

\section{Sample size}

220 patients of Type II diabetes mellitus attending the Medicine OPD for consultation were participated for the study. Based on the literature data [7], the HbAlc level (glycemic control) of the study population was found to be $6.7 \pm 1.3 \%$ which significantly detected out of 455 cases. The sample size was calculated using $80 \%$ power values and $5 \%$ level of significant with mean difference of 0.55 with 6.70 of the original data. So that require sample was 201 . But $10 \%$ excess number was added considering the effectiveness of patients to support the study. The overall sample size was found to be 220 approximately (even number fixed value).

\section{Study population}

Type II diabetes mellitus patients who fulfilled the specified Inclusion and Exclusion Criteria were participated for the study.

\section{Inclusion criteria}

- Aged $\geq 18$ years of age who is diagnosed with Type II Diabetes Mellitus was treated with OHA alone/Insulin alone/ OHA + Insulin (monotherapy or combination therapy) for minimum 4 months.

- Patients who agreed to sign the informed consent form were considered for study.

\section{Exclusion criteria}

- Patients with type 1 diabetes

- Pregnant women, women with gestational diabetes

- Patients with diabetes secondary to other factors like malnutrition, infection, surgery

- Patients who cannot sign the informed consent form

- Hospitalized and/or with psychiatric disorder during the data collection time (since there is a diabetes self-care practices assessment)

\section{Case Record Form (CRF)}

A CRF was prepared to record the information of the Type II diabetes patients attending the medicine outdoor department of Hospital.

\section{In socio-demographic profile}

Age and Gender of the Type II diabetic patients were noted.

\section{Anthropometric and metabolic profile show}

Body Mass Index (BMI). BMI was categorized as normal if BMI was less than $25 \mathrm{~kg} / \mathrm{m}^{2}$, overweight if BMI was between 25 and $29 \mathrm{~kg} / \mathrm{m}^{2}$ and as Obese if BMI was more than $30 \mathrm{~kg} / \mathrm{m}^{2}[8,9]$. Waist Circumference
(WC): The Ideal WC for Males was considered as less than $90 \mathrm{~cm}$ ), and less than $85 \mathrm{~cm}$ for females [10]. Waist/Hip ratio less than 0.9 was considered as ideal [10].

\section{Study procedure}

After explaining the aim of the study to Patients of type II diabetes mellitus attending the medicine outdoor department. Written informed consent was obtained from patient before Study. All data and completed prescriptions were collected on a case record form. Weight, height, and waist circumferences of the type II diabetes patients were recorded. Weight was taken to the nearest $0.5 \mathrm{~kg}$, and height was taken to the nearest $0.5 \mathrm{~cm}$. Body Mass Index (BMI) was calculated as weight in kilograms divided by height in meter Squared. Blood pressure was measured using standardized sphygmomanometers. Blood pressure was recorded while the patient was in a sitting position with the arm at the level of the heart and after 5 min of rest.

Blood samples were collected and glycated Hemoglobin, lipid profile was analyzed using the automated spectrophotometer. If these biochemical parameters were undertaken within last one-two months, the available last readings of HbAlc, fasting blood sugar measurements, and lipid profile [High-Density Lipoprotein (HDL), Low-Density Lipoprotein (LDL), triglyceride, and cholesterol] were abstracted from patients' records. Diabetes self-care was assessed by Diabetes Self-Management Questionnaire (DSMQ) [11]. The data was collected; analyzed and appropriate statistics was applied to obtain meaningful information.

\section{Operational definitions}

Glycemic status was categorized as good glycemic control if $\mathrm{HbAlc}$ was below $7 \%$ and poor glycemic control if $\mathrm{HbAlc}$ was found to be more or equal to $7 \%$. Lipid profile: The $\mathrm{CH}$, HDL and LDL levels were recorded on the CRF. Criteria for abnormal lipid profile levels were based on the Indian Council of Medical Research criteria [12]. Hypercholesterolemia refers to a total cholesterol level $\geq 200 \mathrm{mg} / \mathrm{dl}$. HDL was considered low when the level is below $40 \mathrm{mg} / \mathrm{dl}$ in males and below $50 \mathrm{mg} / \mathrm{dl}$ in females. LDL was considered high when the level was $\geq 100 \mathrm{mg} / \mathrm{dl}$. Hypertriglyceridemia refers to a level $\geq 150 \mathrm{mg} /$ dl. Dyslipidemia was defined as the presence of one or more of the previous abnormalities in serum lipids.

\section{Data analysis and statistical methods}

Descriptive statistics was used for summarizing patient's demographics and survey responses. Differences in HbAlc goal was evaluated by chi-square tests (categorical variables). After finding significant differences in chi-square tests, the Bonferroni function was used to assess individual differences. Independent $t$ test (measurement data) was used to assess the relationship between inadequate glycemic control and potential influencing factors where $\mathrm{P}<0.05$ was considered as statistically significant. The software package used for calculations was SPSS (version 20.0).

\section{Results}

\section{Socio demographic profile of Type II diabetic Patients}

It was found that in age group below 50 years, out of 81 patients studied, 9 (11.1\%) had good glycemic control and $72(88.8 \%)$ had poor glycemic control. In age group 50 to 59 years out of 68 patients, $6(8.8 \%)$ had good glycemic control and $62(91.1 \%)$ had poor glycemic control. In age group above 60 years, out of 71 patients, $3(4.2 \%)$ patients had good glycemic control and $68(95.7 \%)$ had poor glycemic control. 
Out of total males patients studied i.e 126 patients, only $8(6.3 \%)$ patients had good glycemic control and 118 (93.7\%) patients had poor glycemic control. The females patients ( 94 patients) that were studied, $10(10.6 \%)$ had good glycemic control while $84(89.4 \%)$ had poor glycemic control (Table 1).

\section{Anthropometric and Metabolic Profile of Type II diabetic patients}

Anthropometric profile according to BMI (56 patients having normal BMI), 9 (16.1\%) had good glycemic control and $47(83.9 \%)$ had poor glycemic control. Among overweight patients (103 patients), 6 (5.8\%) had good glycemic control and $97(94.2 \%)$ poor glycemic control. Among obese patients (61 patients), only 3 (4.9\%) have good glycemic control while 58 (95.1\%) had poor glycemic control.

Out of the 47 patients, with no central obesity 15 (31.9\%) had good glycemic control and $32(68.1 \%)$ had poor glycemic control. However, majority of the patients had central obesity. Out of 173 patients with central obesity, 3 (1.7\%) had good glycemic control and 170 (98.3\%) had poor glycemic control.

Out of 140 diabetic patients having dyslipidemia, 3(2.1\%) had good glycemic control while $137(97.9 \%)$ had poor glycemic control. While in patients who did not have dyslipidemia (80 patients), 15 (18.8\%) had good glycemic control and 65(81.3\%) had poor glycemic control (Table 2).

\section{Disease profile of Type II diabetic patients}

Out of the 148 patients who had diabetes for less than 7 years, $13(8.8 \%)$ had good glycemic control and 135(91.2\%) had poor glycemic control. Among 72 patients having duration of diabetes more or equal to 7 years, 5 (6.9\%) had good glycemic control and 67 (93.1\%) had poor glycemic control. Out of 100 patients with complications, only 6(6\%) from good glycemic control group had presence of diabetic complications whereas majority, 94 (94\%) from poor glycemic control group had one or more diabetic complications. 157 (96.3\%) patients with poor glycemic control didn't show any diabetic complications and $12(3.7 \%)$ patients with good glycemic control didn't show any complications. $38(86.4 \%)$ patients with poor glycemic control and $6(13.6 \%)$ patients with good glycemic control had presence of one diabetic complications. $7(100 \%)$ patients with poor glycemic control had presence of two complications and $3(100 \%)$ patients with poor glycemic control had more than two complications (Table 3).

\section{Degree of Glycemic control among diabetic patients}

Based on HbAlc values the pattern of glycemic control among diabetic patients was determined $18(8.2 \%)$ patients had good/Ideal glycemic control i.e. HbA1c $<7 \%, 62(28.2 \%)$ had satisfactory glycemic control (HbA1c between 7-8 \%), while majority of patients $140(63.6 \%)$ had unsatisfactory glycemic control (HbAlc value was more than $8 \%$ ). Hence in total 202(91.8\%) had poor glycemic control (which includes patients with satisfactory and unsatisfactory glycemic control) while only $32(8.2 \%)$ had good glycemic control status (Ideal glycemic control) (Figure 1).

\section{Diabetes self-care practices related to glycemic control among diabetic patients}

As shown in Graph No 8, mean \pm SD score for 'glucose management' sub scale was $9.56 \pm 2.12$ among patients with good glycemic control and $7.57 \pm 2.45$ among patients with poor glycemic control. Similarly, for the sub scale 'dietary control' Mean \pm SD score was found to be 8.28 \pm 1.32 among patients with good glycemic control compared to 6.95

Table 1. Socio demographic profile of Type II diabetic patients in relation to glycemic control

\begin{tabular}{|c|c|c|c|c|c|c|}
\hline \multirow[t]{2}{*}{ Sr. No. } & \multicolumn{2}{|c|}{ Parameters } & \multicolumn{2}{|c|}{ Good Glycemic Control HbA1c $<7 \%$} & \multicolumn{2}{|c|}{$\begin{array}{l}\text { Poor glycemic Control } \\
\text { HbA1c }>7 \%\end{array}$} \\
\hline & & & $\mathrm{N}$ & $\%$ & $\mathrm{~N}$ & $\%$ \\
\hline \multirow{3}{*}{1} & \multirow{3}{*}{ Age } & $<50$ Years & 9 & 4.1 & 72 & 32.7 \\
\hline & & 50-59 Years & 6 & 2.7 & 62 & 28.2 \\
\hline & & $\geq 60$ Years & 3 & 1.4 & 68 & 30.9 \\
\hline \multirow{2}{*}{2} & \multirow{2}{*}{ Gender } & Male & 8 & 3.6 & 118 & 53.6 \\
\hline & & Female & 10 & 4.5 & 84 & 38.2 \\
\hline
\end{tabular}

Good Glycemic Control: HbA1c $<7 \%$; Poor Glycemic Control: HbA1c $>7 \%$

Table 2. Anthropometric and Metabolic Profile of Type II diabetic patients related to glycemic control

\begin{tabular}{|c|c|c|c|c|c|c|}
\hline \multirow{3}{*}{ Sr.No. } & \multirow{2}{*}{\multicolumn{2}{|c|}{ Parameters }} & \multirow{2}{*}{\multicolumn{2}{|c|}{\begin{tabular}{|l|} 
Good Glycemic Control \\
HbA1c $<7 \%$ \\
\end{tabular}}} & \multirow{2}{*}{\multicolumn{2}{|c|}{\begin{tabular}{|l|} 
Poor glycemic control \\
HbA1c $>7 \%$ \\
\end{tabular}}} \\
\hline & & & & & & \\
\hline & & & $\mathbf{N}$ & $\%$ & $\mathbf{N}$ & $\%$ \\
\hline \multirow{3}{*}{1} & BMI & Normal & 9 & 4.1 & 47 & 21.4 \\
\hline & \multirow{2}{*}{$\begin{array}{l}\text { (Normal<25, Overweight: } 25-29.9 \text {, } \\
\text { Obese: } \geq 30) \mathrm{kg} / \mathrm{m}^{2}\end{array}$} & Overweight & 6 & 2.7 & 97 & 44.1 \\
\hline & & Obese & 3 & 1.4 & 58 & 26.4 \\
\hline \multirow{2}{*}{2} & W/H Ratio Men $>0.9$ & Normal & 15 & 6.8 & 32 & 14.5 \\
\hline & Women $>0.85$ & Obese & 3 & 1.4 & 170 & 77.3 \\
\hline \multirow{4}{*}{3} & Lipid Profile & Total Cholesterol $(>180)$ & 3 & 1.4 & 82 & 37.3 \\
\hline & $(\mathrm{mg} / \mathrm{dl})$ & $\begin{array}{l}\text { Serum Triglyceride } \\
(>150)\end{array}$ & 2 & 0.9 & 78 & 35.5 \\
\hline & & HDL Cholesterol $(<45)$ & 3 & 1.4 & 89 & 40.5 \\
\hline & & LDL Cholesterol $(>100)$ & 2 & 0.9 & 75 & 34.1 \\
\hline \multirow{2}{*}{4} & \multirow{2}{*}{ Dyslipidemia } & Present & 3 & 1.3 & 137 & 62.2 \\
\hline & & Absent & 15 & 6.8 & 65 & 29.5 \\
\hline
\end{tabular}

BMI: Body Mass Index, HDL: High Density lipoprotein, LDL: Low Density Lipoprotein, Good Glycemic Control: HbA1c $<7 \%$, Poor Glycemic Control: HbA1c $>7$ 
Table 3. Disease profile of Type II diabetic patients related to glycemic control

\begin{tabular}{|c|c|c|c|c|c|c|}
\hline \multirow[t]{2}{*}{ Sr. No } & \multicolumn{2}{|l|}{ Parameters } & \multicolumn{2}{|c|}{ Good Glycemic Control } & \multicolumn{2}{|c|}{ Poor Glycemic Control } \\
\hline & & & $\mathbf{N}$ & $\%$ & $\mathbf{N}$ & $\%$ \\
\hline \multirow{2}{*}{1} & \multirow{2}{*}{ Duration of Diabetes } & $\leq 7$ YEARS & 13 & 5.9 & 135 & 61.4 \\
\hline & & $>7$ YEARS & 5 & 2.3 & 67 & 30.5 \\
\hline \multirow{4}{*}{2} & \multirow{4}{*}{ No of complications } & 0 & 12 & 8.2 & 154 & 70.0 \\
\hline & & 1 & 6 & 0.0 & 38 & 17.3 \\
\hline & & 2 & 0 & 0.0 & 7 & 3.2 \\
\hline & & $>2$ & 0 & 0.0 & 3 & 1.4 \\
\hline \multirow{10}{*}{3} & \multirow{10}{*}{$\begin{array}{l}\text { Diabetic } \\
\text { Complications }\end{array}$} & Cardiovascular & 6 & 2.7 & 94 & 42.7 \\
\hline & & Neuropathy & 00 & 00 & 25 & 11.4 \\
\hline & & Nephropathy & 00 & 00 & 2 & 0.9 \\
\hline & & Catract & 00 & 00 & 9 & 4.1 \\
\hline & & Ulcers & 00 & 00 & 3 & 1.4 \\
\hline & & Hypothyroid & 00 & 00 & 1 & 0.5 \\
\hline & & Hyperpigmentation & 00 & 00 & 2 & 0.9 \\
\hline & & Retinopathy & 00 & 00 & 6 & 2.7 \\
\hline & & Glaucoma & 00 & 00 & 2 & 0.9 \\
\hline & & Cellulitis & 00 & 00 & 2 & 0.9 \\
\hline \multirow{2}{*}{4} & \multirow{2}{*}{ Hypertension } & Yes & 6 & 2.7 & 91 & 41.4 \\
\hline & & No & 12 & 5.5 & 111 & 50.5 \\
\hline \multirow{3}{*}{5} & \multirow{3}{*}{ Treatment Modality } & OHA Alone & 18 & 8.2 & 185 & 84.1 \\
\hline & & Insulin Alone & 0 & 0.0 & 0 & 0.0 \\
\hline & & $\mathrm{OHA}+$ Insulin & 0 & 0.0 & 17 & 7.7 \\
\hline
\end{tabular}

\pm 2.00 patients with poor glycemic $6.95 \pm 2.00$. Mean \pm SD score for 'physical activity' was found to be $5.00 \pm 2.17$ among patients with good glycemic control compared with $4.66 \pm 2.00$ in poor glycemic control. Health care use score (Mean \pm SD) was found to be $5.22 \pm 1.63$ in 'good' and $4.92 \pm 1.48$ among 'poor' glycemic control group. Sum Scale (Mean \pm SD) score was found to be $2.00 \pm 1.03$ among 'good' and $1.47 \pm 0.98$ among 'poor' glycemic control patients group. Total score (Mean \pm $\mathrm{SD})$ was found to be $6.01 \pm 1.03$ among 'good' and $5.15 \pm 1.07$ among 'poor' glycemic control patients group (Figure 2).

\section{Correlation between glycemic control and various variables among patients with Type II Diabetes mellitus.}

Statistically significant difference $(\mathrm{P}=0.044)$ was found between glycemic control and BMI. Similarly statistically significant difference $(\mathrm{P}<0.001)$ was found between glycemic control and central obesity. In metabolic profile, statistically significant difference $(\mathrm{P}<0.001)$ was found between glycemic control in relation with dyslipidemia. Among diabetes selfcare practices statistically significant difference ( $\mathrm{P}=0.003$ ) was found between patients with good and poor glycemic control in relation with glucose management with dietary control $(\mathrm{P}=0.006)$. Similarly, statistically significant difference $(\mathrm{P}=0.028)$ was found among patients with good and poor glycemic control in relation with sum scale and total score $(\mathrm{P}=0.001)$. No significant difference between the variables age, gender, socio demographic profile, duration of diabetes, treatment modality, no of complications was observed between patients with poor and good glycemic control. Also In diabetes self-care practice (physical activity and health care use) no statistical significant difference was found between patients with poor and good glycemic control

\section{Discussion}

The present study was a hospital based cross sectional study conducted in the diabetes clinic of tertiary care hospital. The primary objective of the study was to assess the glycemic control among diabetic patients attending the medicine outpatient department. In addition,

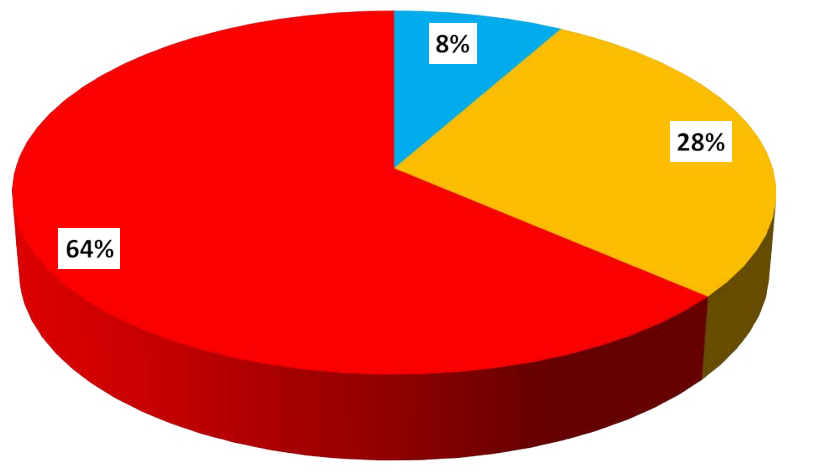

$\square \operatorname{IDEAL}(<7) \quad$ SATISF ACTORY (7-8) $\square$ UNSATISFACTORY (>8)

Figure 1. Degree of glycemic control among patients with diabetes. HbAlc $<7 \%$ is good glycemic control. HbAlc $>7 \%$ poor glycemic control which includes satisfactory and unsatisfactory glycemic control

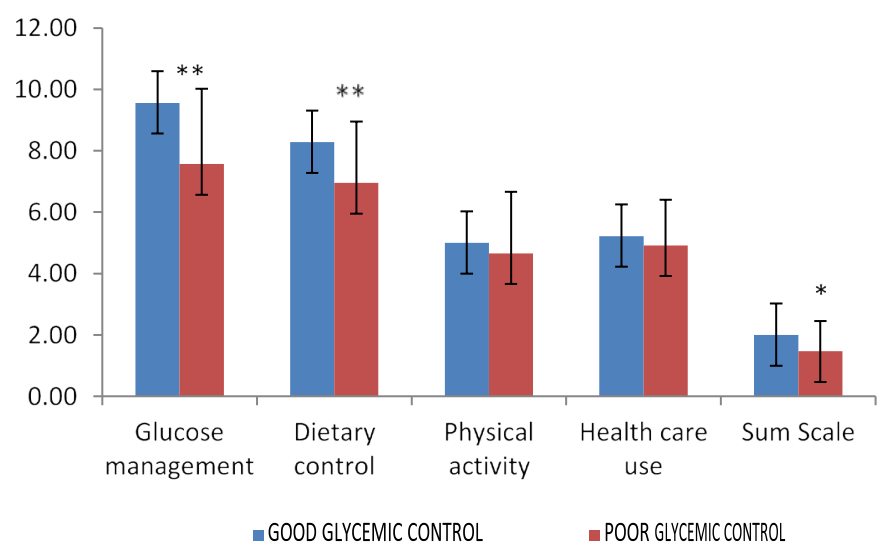

Figure 2. Diabetes Self Care Practice Related to Glycemic control among patients with diabetes. HbA1c $<7 \%$ is good glycemic control. HbA1c $>7 \%$ poor glycemic control which includes satisfactory and unsatisfactory glycemic control 
the various factors affecting glycemic control and their relationship with glycemic control in patients of Type II diabetes mellitus was determined.

\section{Profile of patients with Type II diabetes mellitus}

Two hundred and twenty patients participated in the study. Majority of the respondents (36.8\%) were below 50 years followed by age above 60 years $(32.3 \%)$. This finding is inconsistent with findings of Angel Dominic et al. [13] where majority of studied population was between 40 to 60 years and Jambu Jain et al. [14] where most of the study population was between 50 to 60 years. In the present study the male to female ratio was found to be 1.34 \{male patients, $57.3 \%$ : female patients, $42.7 \%$. This trend is similar to study conducted in India Gopinath B el al. [15].

Majority $(67.3 \%)$ of the patients had diabetes below or equal to 7 years, while $32.7 \%$ had diabetes for more than 7 year which is similar to the study findings by Gopinath B el al. [15] where $60.2 \%$ of the patients had diabetes for less than 7 years.

Overall prevalence of both macrovascular and microvascular complications was high in the study population. The cardiovascular complications were most common (45.5\%), followed by neuropathy (11.4\%). Nephropathy was found in $(0.9 \%)$ and cataract in $(4.1 \%)$ cases. Out of the total respondents studied, $2.7 \%$ had retinopathy, $1.4 \%$ had ulcers, $0.5 \%$ patient had hypothyroidism ,0.9\% had hyper pigmentation, $0.9 \%$ glaucoma which concurs with study conducted by Viswanathan Mohan et al. [16]. The authors reported retinopathy (34.4 $\%)$; nephropathy, (20.4\%); neuropathy, (28.8\%); peripheral vascular disease, (65.4\%) and cardiovascular diseases (100\%) among diabetic patients. Hence cardiovascular complication was the most common complication encountered in patients with Type II diabetes mellitus. Different studies from India and other countries have reported a similar observation about the co-morbidity prevalent in patients with diabetes [14,17].

Diabetes Self-Management Questionnaire (DSMQ) was used to assess the self-care practices among the Type II diabetic patients. DSMQ determined self-care activities mean score for sub scales: 'Glucose Management', 'Dietary Control', Physical Activity', 'HealthCare Use' and 'Sum Scale' the mean score obtained in their sub scale were similar to study by Katja Brenk-Franz et al. [18].

\section{Glycemic control}

Good metabolic control, right from the time of diagnosis of diabetes, is key to the prevention of chronic complications. Measurement of glycated hemoglobin (HbAlc) is now universally accepted as the most reliable indicator of long-term glycemic control because it accurately reflects an individual's blood glucose levels over the preceding 2-3 months. Assessment of the level of diabetes control in a population using $\mathrm{HbA} 1 \mathrm{c}$ is a good indicator of the quality of diabetes care available to the population [19]. Assessment of the current glycemic status and the burden of diabetes related complications are therefore important in order to allocate community and health resources in any country and plan interventions to address the issues related to poor glycemic control. While there is lot of data in Western countries, such data are limited from developing countries like India [10].

The present study assessed the glycemic status among Type II diabetic patients and categorized them as having good glycemic control (HbAlc $<7 \%$ ) and poor glycemic control HbAlc (>7\%). In the present study as per the American diabetes association guidelines proportion of patients who have good (ideal)glycemic control were only $8.2 \%$. Patients with poor glycemic control were sub grouped as those with satisfactory (HbA1c:7-8 \%) and unsatisfactory (HbAlc >8\%) glycemic control which was found to be $28.2 \%$ and $63.6 \%$ respectively. Despite the regular medical management, most of the patients $(91.8 \%)$ were found to have poor glycemic control, i.e., were having HbAlc more than $7.0 \%$. Similar observation was recorded in other study conducted by Gopinath B et al. [15] and Yonusmullug et al. [20].

Although glycemic control is known to reduce complications associated with diabetes, it remains an elusive goal for many patients with diabetes. The objective of this study was to therefore also to identify factors associated with sustained poor glycemic control, such as treatment modality (Oral Hypoglycemic agents, Insulin, $\mathrm{OHA}+$ Insulin), risk factors (Hypertension, Dyslipidemia), sociodemographic (Age, Gender, Socio-economic status), metabolic (Lipid Profile), anthropometric (BMI, Waist Circumference) and disease profile (complications of diabetes) as well as the diabetes self-care practices (Glucose Management, Dietary Control, Physical Activity and Health-Care Use). Such baseline data will help us to understand the issues related to poor glycemic control and help in planning future interventions to address these problems.

\section{Variables impacting glycemic control}

Age, Gender, duration of diabetes, number of diabetic complications and treatment modality was not statistically significantly associated with glycemic control. These variables were not considerably different between the diabetic patients with poor and good glycemic control status. According to BMI, diabetic patients who were categorized as obese were more in the poor glycemic control group (95.1\%) as compared to good glycemic control group (4.9\%). Similar observation was seen in study by Gopinath B et al. [15], Maysaa Khattab et al. [4]. They found that most of obese patients had poor glycemic control. Also, majority (98.3\%) of the patients who had central obesity had poor glycemic control. The results concur with findings by Luis A Vázquez et al. [21].

In the present study statistically, significant difference $(\mathrm{P}=0.044)$ was found between glycemic control and obesity. Similar observation was reported by Gopinath B et al. [15], Viswanathan Mohan et al. [16], Sasisekhar T.V.D et al. [22]. Most importantly almost all the diabetic patients with dyslipidemia $(97.9 \%)$ had poor glycemic control. Thus, statistically significant difference $(\mathrm{P}=0.03)$ was found between dyslipidemia and glycemic control as observed previously by Yonas Mullugeta et al. [20], Gopinath B et al. [15], Maysaa Khattab et al. [4].

The American Association of Diabetes Educators Outcome Standards for Diabetes Education specifies self-care management behavior as the key glycemic control outcome. Effective selfmanagement is one (but not the only) contributor to longer term, higher-order outcomes such as clinical status (e.g., control of glycemia, blood pressure, and cholesterol), health status (e.g., avoidance of complications), and subjective quality of life. Thus, patient selfmanagement behaviours are at the core of the outcomes evaluation. In the present study a validated tool: Diabetes Self-Management Questionnaire (DSMQ) was used to assess self-care activities. The DSMQ is a 16-item questionnaire designed to assess four subscales, 'Glucose Management' (GM), 'Dietary Control' (DC), 'Physical Activity' (PA), and 'Health-Care Use' (HU), as well as a 'Sum Scale'.

Statistically significant difference $(\mathrm{P}=0.006),(\mathrm{P}=0.003)(\mathrm{P}=0.028)$ was found between patients with good and poor glycemic control in 
relation with 'dietary control', 'glucose management' and 'sum scale' respectively. Results are consistent with glucose management, dietary control, physical activity measures in the study by Maysaa Khattab et al. [4]. However in the subscales of self-care practice questionnaire 'physical activity' and 'health care use', no statistically significant difference was found between in relation to glycemic control status (poor Vs good glycemic control). Thus, according to these results, patients with 'good glycemic control' reported significantly more 'Glucose Management' and 'Dietary Control', than those with 'poor glycemic control'. Correspondingly, in this group the mean 'Sum Scale' score was significantly higher.

Effective educational and therapeutic approaches should be focused on enhancing dietary control, glucose management, weight control, management of dyslipidaemia, and optimizing glycemic control. Thus there is a need to increase awareness among patients and healthcare providers regarding the importance of good glycemic control, so that decisions on treatment escalation can be taken and implemented at the appropriate time and patients can protected from the ill effects of the accumulated and potentially avoidable glycemic burden.

To summarize, majority of the diabetic patients had poor glycemic control values (91.8\%). The variables found to influence the outcome of glycemic control in the present study were presence of dyslipidemia, obesity, 'Glucose Management' and 'Dietary Control' diabetes self-care practices. Therefore, the present study determined the status of current glycemic control outcomes and identified factors that influence good glycemic control among type 2 diabetes mellitus patients.

The study had some limitations. One of the limitations was that confounding factors, such as diet and the quantification of sugar intake, were not carried out. There was no patient follow up or active interventions administered to diabetic patient with poor glycemic control that could impact glycemic outcomes. Nonetheless the results are interesting and meaningful data that has immense potential clinical implications. Such information will help to plan interventions for implementation of an intensive approach to rapid glycemic control at the level of the patient, physician and Institute.

\section{Conclusion}

Majority of type II diabetes mellitus patients had poor glycemic control. Factors affecting the glycemic control were identified in the study. BMI, central obesity, dyslipidemia was found to be factors significantly affecting glycemic control. Among the diabetes self-care practice sub scales, 'glucose management' and 'dietary control' were found to significantly affect glycemic control. However other variables such as age, gender, socioeconomic class, number of complication, treatment modality did not impact the glycemic control status of the Type II diabetic patients.

\section{Data availability}

Data available upon request, through the corresponding author. All other data arising from this study are contained within the manuscript and supplementary information files.

\section{References}

1. Cho NH, Shaw JE, Karuranga S, Huang Y, da Rocha Fernandes JD, et al. (2018) IDF Diabetes Atlas: Global estimates of diabetes prevalence for 2017 and projections for 2045. Diabetes Res Clin Pract 138: 271-281. [Crossref]

2. Anjana RM, Ali MK, Pradeepa R, Deepa M, Datta M, et al. (2011) The need for obtaining accurate nationwide estimates of diabetes prevalence in India - rationale for a national study on diabetes. Indian J Med Res 133: 369-380. [Crossref]
3. Kumar, Vinay, and Stanley L (2007) 1915- Robbins. Robbins Basic Pathology. Philadelphia, PA, Saunders/Elsevier.

4. Khattab M, Khader YS, Al-Khawaldeh A, Ajlouni K (2010) Factors associated with poor glycemic control among patients with type 2 diabetes. J Diabetes Complications 24: 84-89. [Crossref]

5. Kamuhabwa A Charles E (2014) Predictors of poor glycemic control in type 2 diabetic patients attending public hospitals in Dares Salaam. Drug Healthc Patient Saf 6: 155165. [Crossref]

6. Goudswaard AN, Stolk RP, Zuithoff P, Rutten GE (2004) Patient characteristics do not predict poor glycaemic control in type 2 diabetes patients treated in primary care. Eur $J$ Epidemiol 19: 541-545. [Crossref]

7. Zhang SL, Chen ZC, Yan L, Chen LH, Cheng H, et al. (2011) Determinants for inadequate glycaemic control in Chinese patients with mild-to-moderate type 2 diabetes on oral antidiabetic drugs alone. Chin Med J(Engl) 124: 2461-2468. [Crossref]

8. American Diabetes Association (2016) Standards of Medical Care in Diabetes. http:// care.diabetesjournals.org/content/39/Supplement_1.S13.full.pdf [22 Mar 2016]

9. Diagnostic Criteria ICMR Guidelines for Management of Type 2 Diabetes. Available from: http://icmr.nic.in/guidelines_diabetes/section3.pdf

10. World Health Organization Expert Committee (1995) Physical Status: The Use and Interpretation of Anthropometry; Technical Report Series No. 854, Geneva 1995: 427-438.

11. Schmitt A, Gahr A, Hermanns N, Kulzer B, Huber J, et al. (2013) The Diabetes SelfManagement Questionnaire (DSMQ): development and evaluation of an instrument to assess diabetes self-care activities associated with glycaemic control. Health Qual Life Outcomes 11: 138. [Crossref]

12. Targets of glycemic control (2016) ICMR Guidelines for Management of Type 2 Diabetes- 2005. Available from: http://icmr.nic.in/guidelines_diabetes/section4.pdf

13. Dominic A, Joseph J, Augustin RM, Begum R, Nanjwade BK (2016) Study of drug use evaluation on Oral Antihyperglycemic Agents in Type 2 Diabetes Mellitus and their potential Drug-Drug Interactions. World J Pharm Pharmaceut Sci 5: 1884-1896.

14. Jain J, Sharma P, Jain J, Raja M (2016) Utilization pattern of oral hypoglycemic agents for diabetes mellitus type 2 patients attending out-patient department at tertiary care centre in Bhopal. Int J Basic Clin Pharmacol 5: 1826-1830.

15. Gopinath B, Sri Sai Prasad M, Jayarama N, Prabhakara K (2013) Study of factors associated with poor glycemic control in Type -2 Diabetic patients. Glob J Med Pub Health.

16. Mohan V, Shah S, Saboo B (2013) Current glycemic status and diabetes related complications among type 2 diabetes patients in India: data from the A1chieve study. $J$ Assoc Physicians India 61: 12-15. [Crossref]

17. Satpathy SV, Dutta S, Upreti B, Bhutia N, Sharma DK (2014) Utilization and Adverse reaction profile of Anti-diabetic drugs in a Tertiary Care Hospital in East Sikkim: A Cross-Sectional Observational Study. In Indian journal of pharmacology 46: S102-S102.

18. Brenk-Franz K, Strauss B, Tiesler F, Fleischhauer C, Ciechanowski P, et al. (2015) The Influence of Adult Attachment on Patient Self-Management in Primary Care--The Need for a Personalized Approach and Patient-Centred Care. PLoS One 10: e0136723. [Crossref]

19. Unnikrishnan R, Rema M, Pradeepa R, Deepa M, Shanthirani CS, et al. (2007) Prevalence and risk factors of diabetic nephropathy in an urban South Indian population the Chennai Urban Rural Epidemiology Study (CURES 45). Diabetes Care 30: 20192024. [Crossref]

20. Mullugeta Y, Chawla R, Kebede T, Worku Y (2012) Dyslipidemia associated with poor glycemic control in type 2 diabetes mellitus and the protective effect of metformin supplementation. Indian Journal of Clinical Biochemistry 27: 363-369.

21. Vázquez LA, Rodríguez A, Salvador J, Ascaso JF, Petto H, et al. (2014) Relationships between obesity, glycemic control, and cardiovascular risk factors: a pooled analysis of cross-sectional data from Spanish patients with type 2 diabetes in the preinsulin stage. BMC Cardiovasc Disord 14: 1. [Crossref]

22. Sasisekhar TV, Shabana S, Bhargav SY (2013) Gender: Does it have role has role in glycaemic control and diabetic distress in type 2 diabetes. IOSR-JDMS 4: 48-51.

Copyright: (C2018 Kakade AA. This is an open-access article distributed under the terms of the Creative Commons Attribution License, which permits unrestricted use, distribution, and reproduction in any medium, provided the original author and source are credited. 